\title{
HARVESTING ENERGY AND HYDROGEN FROM MICROBES
}

\author{
Paweł Sobieszuk ${ }^{*}$, Anna Zamojska-Jaroszewicz, Andrzej Kołtuniewicz \\ Warsaw University of Technology, Faculty of Chemical and Process Engineering, Waryńskiego 1, \\ 00-645 Warszawa, Poland
}

This article presents a critical mini-review of research conducted on bioelectrochemical reactors with emphasis placed on microbial fuel cells (MFC) and microbial electrolysis cells (MEC). The principle of operation and typical constructions of MFCs and MECs were presented. The types of anodes and cathodes, ion-selective membranes and microorganisms used were discussed along with their limitations.

Keywords: clean energy, microbial fuel cell, microbial electrolysis cell, hydrogen

\section{INTRODUCTION}

The progress of civilization presents us with many challenges. The growing energy requirements force us to search for cheap, renewable and environmentally friendly methods of its production. Currently, the most commonly used fossil fuels are hard coal, oil and natural gas. Their excavation is associated with land degradation and their treatment causes the release into the atmosphere large quantities of harmful chemicals such as carbon dioxide, sulphur dioxide or nitrogen oxide. Fossil fuels are nonrenewable, and their lifetime is limited. Some forecasts predict that oil reserves will be exhausted within the next few decades, and the only alternative is renewable energy. Electrochemical bioreactors may be one of those "green" energy sources. These devices utilise microorganisms as catalysts for an electrochemical reaction. Bioelectrochemical reactors (BER) reprocess organic matter to electricity using microorganisms. An appropriate final electron acceptor is used, depending on the type of chemical compounds. BERs can be used for different purposes, and their primary function was to produce electricity. Currently, they are used to produce hydrogen and other useful compounds such as methane or ethanol. However, they can also be used in electrochemically supported denitrification. But the greatest advantage of BER is its ability to simultaneously carry out a variety of processes. Sewage and other waste substances can be used as a substrate for microbial growth. This is the technology of the future, because it allows to combine the degradation of waste together with the production of clean energy, which meets all the demands of clean technologies and sustainable development.

\section{2. TYPES OF BIOELECTROCHEMICAL REACTORS}

Schemes of typical bioelectrochemical reactors are presented in Fig.1. The literature usually distinguishes between microbial fuel cells and microbial electrolysis cells. BER is called a fuel cell if it generates power. When an electrochemical reaction requires external energy, we call them electrolytic cells. (Hamelers et al., 2010). Microbial fuel cells (MFC, Fig. 1a) are used for simultaneous wastewater treatment and power generation. In anode chamber anaerobic microorganisms perform substrate 
oxidation process by which electrons and protons are formed. Released electrons are transferred to the anode and flow through an external circuit to the cathode. Every electron that flows externally to the cathode must be caught by a proton, which flows from the anode to the cathode chamber through the ion exchange membrane. In cathode chamber, electrons and protons are transferred to the final electron acceptor. Microbial electrolysis cells (MEC, Fig. 1b) are used for hydrogen production often with combination with organic substrate degradation.
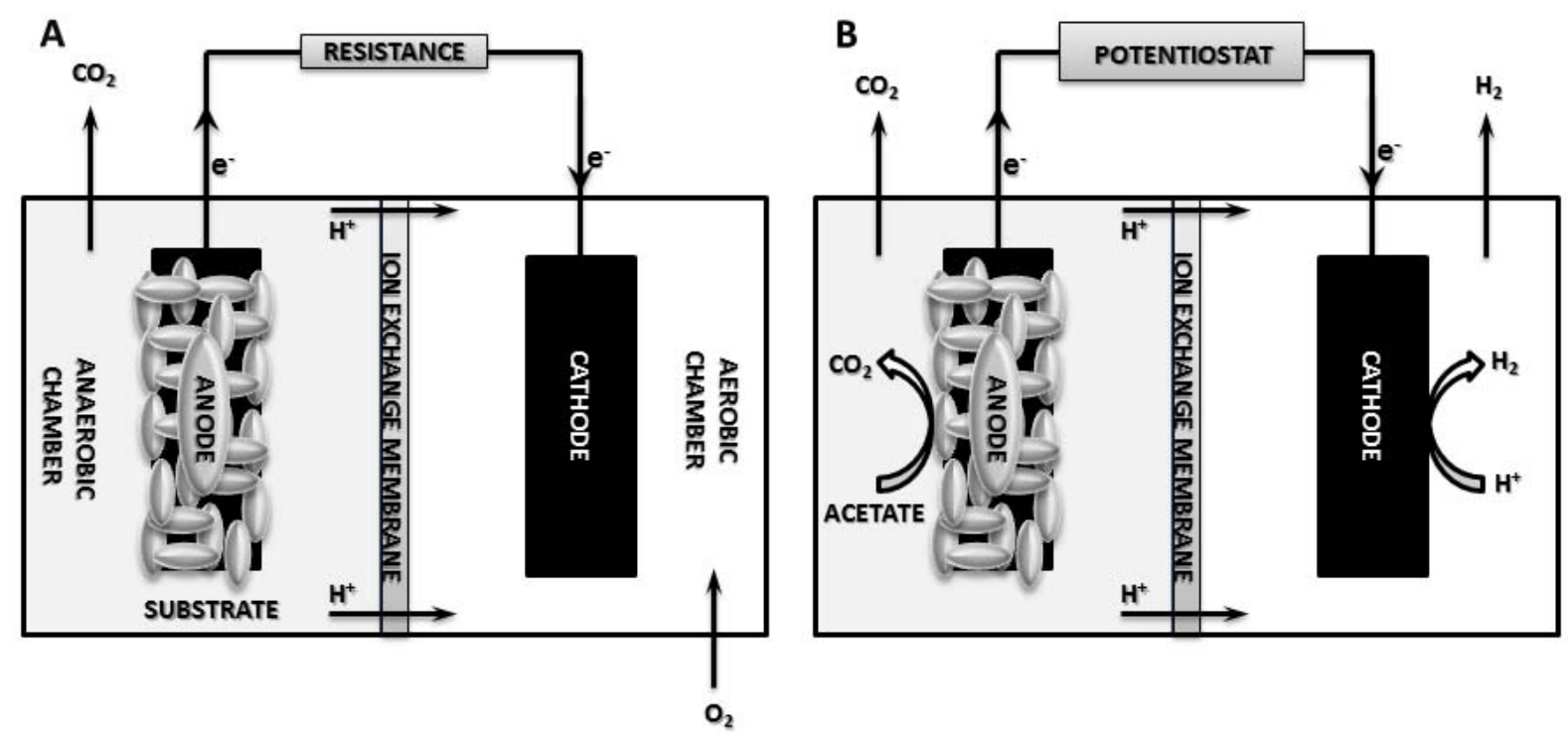

Fig. 1. Schematic diagram of typical bioelectrochemical reactors: A - microbial fuel cell (MFC), $\mathrm{B}$ - microbial electrolysis cell (MEC)

MFCs in contrast to MECs require external power, as in classical electrolysis. Anodic reaction of the MECs is identical with the reaction of MFCs, except that the cathodic reaction leads to the formation of hydrogen in the MFCs. The use of microorganisms allows for more efficient operation of electrolysis with less external energy consumption.

Regardless of type, all reactors of this type have in common the anaerobic oxidation of substrates in the anode chamber. Therefore, the overall process within reactor depends on which reaction takes place at the cathode. Currently the following types of BER can be identified:

- Microbial fuel cells (MFCs) - where the main objective is to obtain electrical energy (Freguia et al., 2010). Typical designs are shown in Fig. 2. As can be seen different configurations and shapes are possible.

- Microbial electrolysis cells (MECs) - which are used for the production of hydrogen (Logan et al., 2006). The apparatus structure is similar to MFC.

- Electrosynthesis microbial cells (MESs) - that are used for the synthesis of organic compounds (Nevin et al., 2010). At the cathode, carbon compounds are reduced to more complex forms. Reactors of this type, as well as MEC, require an external input of energy.

- Micro-sized microbial fuel cells ( $\mu \mathrm{MFCs})$ - include mL-scale and $\mu \mathrm{L}$-scale setups. The mL-scale MFCs allow for achieving higher values of current and volumetric power densities compared to macro-scale MFCs. The existing $\mu \mathrm{L}$-scale MFCs, due to their high internal resistance, exhibit significantly worse characteristic. However, they show a great potential in a rapid screening of electromaterials and electrochemically active microbes (Wang et al., 2011). 
A

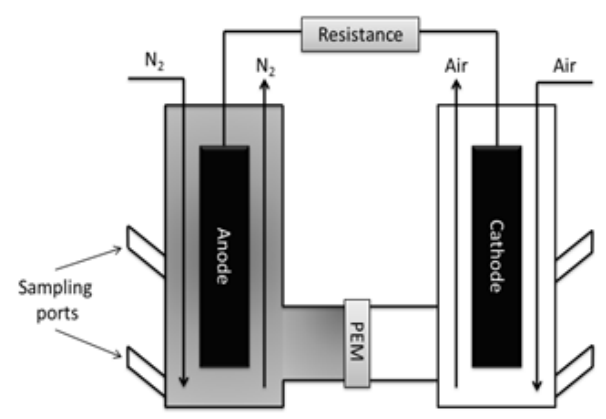

B

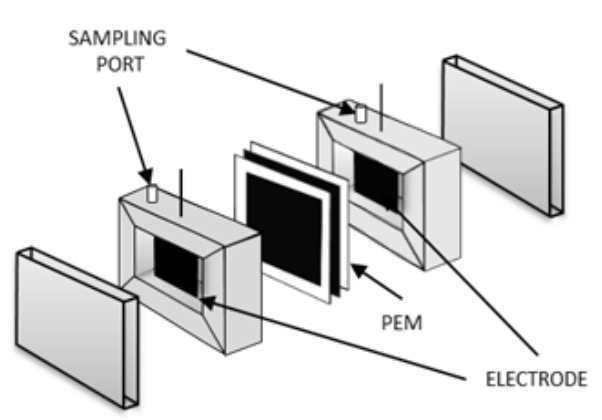

C
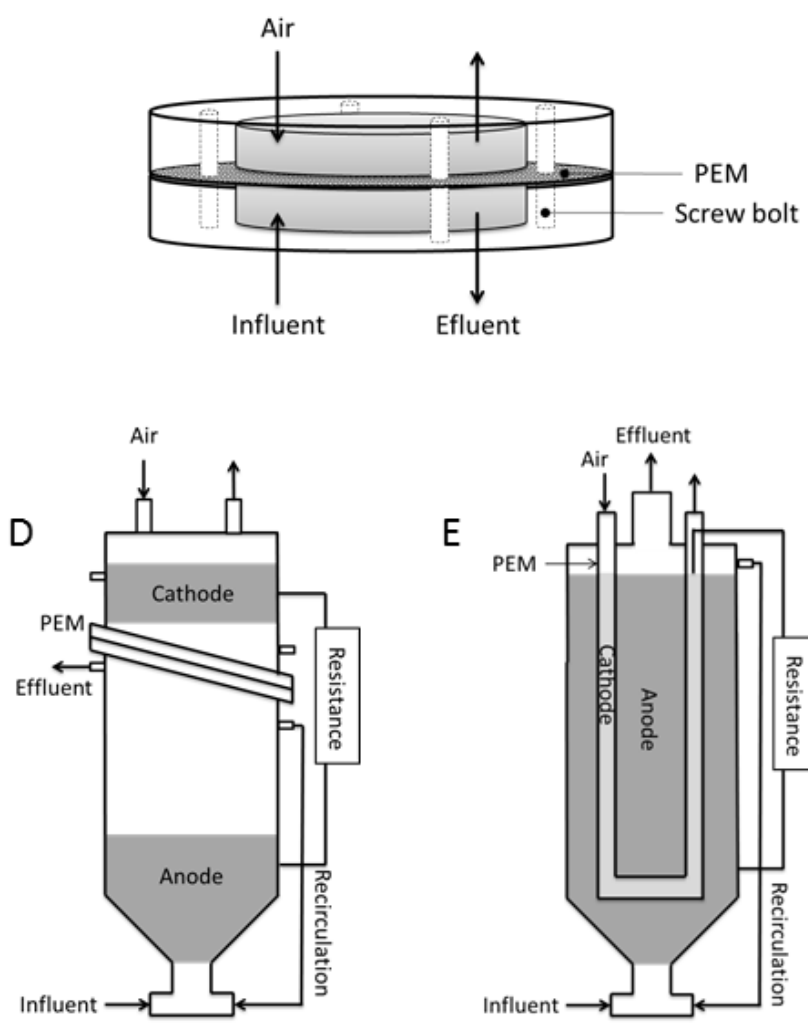

$E$

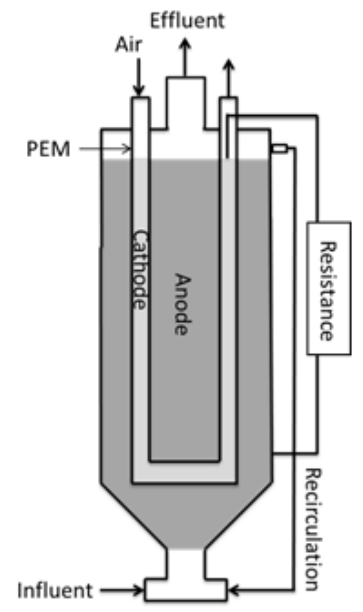

Fig. 2. Schemes of different MFC designs

\section{ELEMENTS OF BIOELECTROCHEMICAL REACTORS}

Satisfactory BER performance depends on the proper selection of components of the apparatus including electrodes, membranes and microorganisms.

\subsection{Anodes}

Lefebvre et al. (2011) show that BER is basically a biofilm reactor and anode materials should meet all the requirements of such applications (to be chemically stable, have a large surface area and high porosity, not be sensitive to impurities and be biocompatible). An additional feature here is the fact that high conductivity is required together with resistance to corrosion. Therefore it makes it impossible to use many metals as the electrode building materials. The surface structure should not impair the bacteria ability for electron transfer - the impact of electron transport mechanism (direct contact, nanowires, and mediators). What is more, a perfect anode material should be cheap and easy to manufacture. The search for a material that meets all these requirements is still on-going. Currently, the most commonly used material for this purpose is carbon in the form of paper, cloths, fibres, meshes and reticulated vitreous carbon (RVC), which is promising owing to its very high conductivity.

Graphite rods, felts, foams, plates and sheets are also widely used. Tab. 1 shows typical values of conductivity for some carbon materials mentioned above. The compact structure and smooth surface of plane anodes (plates and sheets) facilitate quantitative measurements per unit of anode surface area. More packed materials such as felts and foams have much more developed surface and biomass concentration can be higher, but the measurement of this concentration is complicated. The highest specific surface area of anodes can be obtained by using graphite fibre brush electrodes. The core of 
such a brush has to be made from non-corrosive metal e.g. titanium. A carbon plane anode allows to obtain the power per anode area in range: $600 \div 3290 \mathrm{~mW} / \mathrm{m}^{2}$, and per anode chamber volume about 45 $\mathrm{W} / \mathrm{m}^{3}$. In the case of packed materials the power per anode chamber volume was in the range $5 \div 386$ $\mathrm{W} / \mathrm{m}^{3}$ (Wei et al., 2011). Metal anodes are also used. Because of the non-corrosive requirement many metals were ruled out as anode materials. Only stainless steel, titanium, platinum and gold are proper for these applications. However, metal adhesive properties are insufficient for biofilm formation. Even in the extreme case (an uncoated titanium plate) no current was observed (ter Heijne et al., 2008). There are several surface modification methods for improving bacterial attachment and electron transfer to the anode including: physical or chemical modification (Tang et al., 2011; Wang et al., 2009), addition of conductive or electro-active coatings (Liang et al., 2011), using metal-graphite composite electrodes (Lowy and Tender, 2008). Some preliminary investigations were conducted on conductive polymer coated anodes, although the performance of these systems was unsatisfactory. Some attempts have been made on reducing metabolite electron losses by using dual-anode electrodes (Kim et al., 2011). Two bacterial anodes were jointly installed within one anode chamber. The first one was enriched by glucose utilising microbial population, and the other by propionate utilizing microbial. It allowed for Columbic efficiency improvement up to $59 \%$.

Table 1. Conductivity values for different carbon and graphite materials

\begin{tabular}{|c|c|c|}
\hline No. & Material & $\begin{array}{c}\text { Conductivity } \\
{\left[\Omega^{-1} \mathrm{~cm}^{-1}\right]}\end{array}$ \\
\hline 1 & copper & 10 \\
\hline 2 & carbon paper & 1.250 \\
\hline 3 & carbon cloth & 0.450 \\
\hline 4 & graphite fibre & 0.625 \\
\hline 5 & conductive polymer sheet & 0.008 \\
\hline 6 & RVC & 200 \\
\hline
\end{tabular}

One of the most recent investigations was performed on high-performance mediator-less MFC with graphene/carbon cloth anode. Liu et al. (2012), investigated MFC with anode as: graphene coated carbon cloth and pure carbon cloth. Graphene application delivered 2.7 fold higher power density and even 3.0 fold higher cell voltage than a plain carbon cloth anode (Fig.3).

A

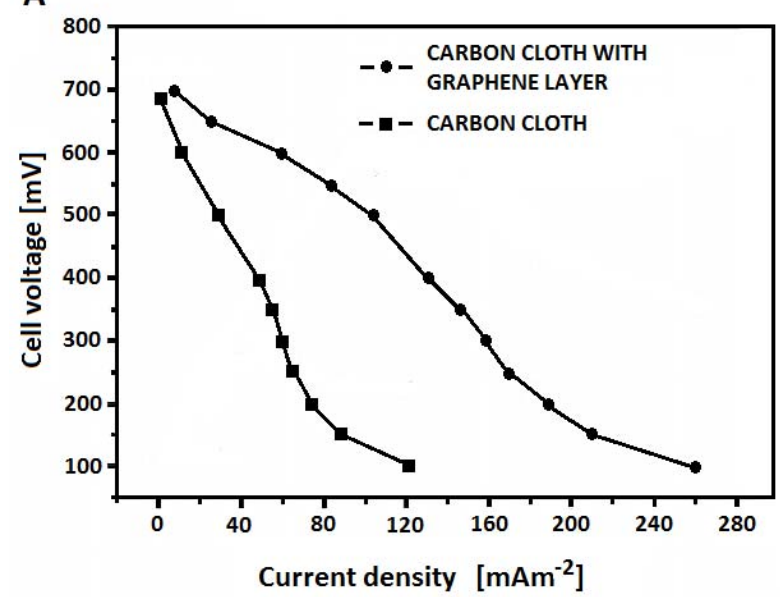

B

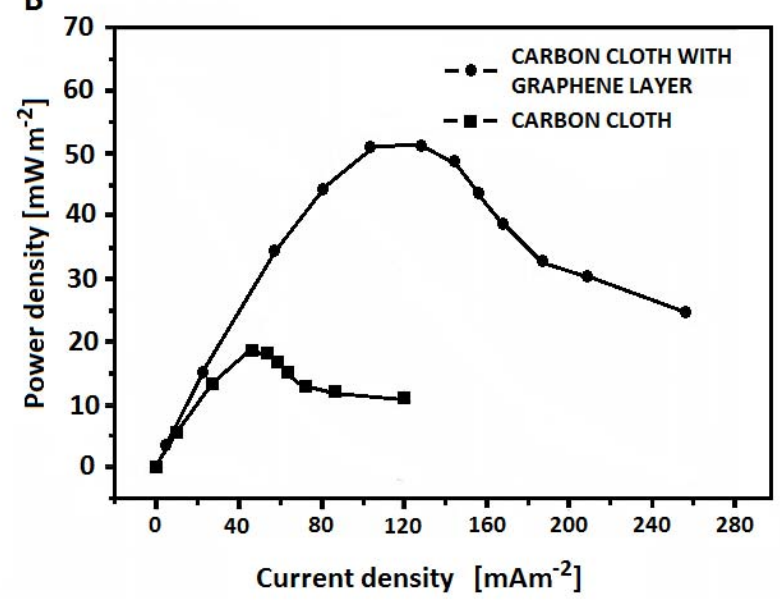

Fig. 3. Comparison of work of MFC with and without graphene layered anode: A - cell voltage, B - power density (Liu et al., 2012) 


\subsection{Cathodes}

The most commonly used MFC cathodes are air-cathodes, aqueous air-cathodes and bio-cathodes. Aircathodes allow to obtain the power per cathode area in range: $331-1610 \mathrm{~mW} / \mathrm{m}^{2}$. In the case of aqueous air-cathode the range of power per electrode area is: $33-788 \mathrm{~mW} / \mathrm{m}^{2}$ (Wei et al., 2011). Cathodes in MFCs are made of similar materials to those of anodes. Additionally cathodes contain a catalyst to improve the reduction process (Lefebvre et al., 2011; Logan, 2010). The MFC catalyst that gives the best results is platinum. It reduces energy losses and increases the pace of reduction of oxygen, both dissolved in water and contained in the air. However, platinum is too expensive to use it on a larger scale. In order to reduce costs, its content may be reduced to $0.1 \mathrm{mg}$ per $\mathrm{cm}^{2}$ of the cathode (Logan et al., 2006). New catalysts that contain no precious metals seem to be much more promising. They are based on metallo-organic compounds containing cobalt and iron. Examples of such catalysts are ferricyanide and anthraquinone-2,6-disulfonate. The cathode material for oxygen reduction may also be activated carbon (Logan, 2010). It has a poorer oxygen reduction rate compared with other carbon materials with platinum addition, but has a much larger surface area. It is applied in combination with a metal sponge, which serves as current collector. Platinum also gives way to new catalysts in MFCs. Electrodes made of nickel or stainless steel achieve comparable or even better results. Electrodes made of stainless steel brushes give similar hydrogen production rates to a flat carbon electrode with platinum addition. However, there is a problem with gas bubbles that remain attached on the surface of the cathode. Good results are obtained with alloys of nickel and molybdenum. Tungsten carbide may also be useful although the problem is its high susceptibility to corrosion in phosphate buffer at neutral $\mathrm{pH}$ (Logan, 2010). Microorganisms can also play the role of catalysts. Their presence alleviates the need for using expensive metal, reduces overvoltage and allows for greater efficiency of the process (Freguia et al., 2010; Nevin et al., 2010; Rozendal et al., 2008; Yang et al., 2011).

Conductive polymers, which were not yet used as building blocks of anodes, can be a good material for building cathodes. They show good catalytic properties for oxygen reduction and are suitable as support for biofilm development. They contain a functional group - $\mathrm{OH}$, which makes them less sensitive to $\mathrm{pH}$ changes in the cathode chamber. They also contain $-\mathrm{NH}_{3}$ groups which help in a rapid colonisation of the cathode surface by microorganisms (Li et al., 2012).

\subsection{Membranes}

Cation exchange membranes are the most commonly used separators in electrochemical bioreactors. As noted above, a typical bioelectrochemical reactor BER is composed of two compartments separated by a selective proton exchange membrane. In the anode chamber, there is decomposition of organic material by anaerobic bacteria with the release of carbon dioxide, protons and electrons. While the membrane should pass only protons, electrons migrate to the cathode chamber by an external electrical circuit. In the cathode chamber, oxygen reduction takes place with the participation of electrons, and then reaction with protons, to form water. In both chambers, typically, there are additives which are used to facilitate these reactions. A properly functioning proton-exchange membrane is not permeable to these substances along with the growth substrates, oxygen or electrons between the two chambers. Such membranes should also be resistant to biofilm obliteration. To keep the membrane transport process in proper condition, the flow of electrons in an external circuit must be compensated by an equal number of protons transported at the same time through the membrane. Common problems of proton-exchange membrane are as follows:

- diffusion of oxygen and buffers with cathode to the anode chamber must be eliminated,

- do not allow diffusion through the membrane of chemical oxidants such as ferricyanide or MN (IV), which must be constantly replenished,

- do not allow diffusion of substrates and carbon dioxide from the anode to the cathode chamber, 
- do not let a membrane lose its separation properties due to the preferential saturation of sulfonic groups, cations other than protons,

- do not let a membrane lose its separation properties due to the aging of the membrane, degree of fouling and biofilm overgrowing,

- do not let a membrane lose its separation properties due to the $\mathrm{pH}$ reduction in the anode chamber, with a corresponding increase of $\mathrm{pH}$ in the cathode chamber.

The most popular membranes for BER are made of Nafion (Rozendal et al., 2006), which is sulfonated tetrafluorethylene copolymer, consists of a hydrophobic fluorocarbon backbone $\left(-\mathrm{CF}_{2}-\mathrm{CF}_{2}-\right)$. A high cation conductivity of Nafion can be explained by a high concentration of these negatively charged sulfonate groups in the membrane ([- $\left.\left.\mathrm{SO}_{3}{ }^{-}\right] \quad 1.13 \mathrm{~mole} / \mathrm{L}\right)$. When in contact with water, the hydrogen proton $\left(\mathrm{H}^{+}\right)$detaches and flights from one sulfonic molecule $\left(\mathrm{SO}_{3}{ }^{-}\right)$to another and thus acts like an electrolyte in the presence of water. Therefore, Nafion- 117 transfers $\mathrm{H}^{+}$across the PEM to the cathode, but does not allow electrons to cross. In order to effectively meet all of the above requirements during durable conditions of work and to ensure membrane efficiency it should be stored in an appropriate manner. For example, Nafion membranes are stored in deionised water. Their regeneration requires boiling in $30 \% \mathrm{H}_{2} \mathrm{O}_{2}$ and then soaking in $0.5 \mathrm{M} \mathrm{H}_{2} \mathrm{SO}_{4}$, and then again soaking with deionised water, for 1 hour, to prevent swelling of the membrane before use. Typical membranes are Nafion- 117 which has a pore size of $50 \AA\left(10^{-10} \mathrm{~m}\right)$ and power density $7.63 \mathrm{~mW} / \mathrm{m}^{2}$ and I.C.E. 450 or Hybond ${ }^{\mathrm{TM}}-\mathrm{N}$, which has power densities between $12-14 \mathrm{~mW} / \mathrm{m}^{2}$ pore size of 0.45 microns. There are other commercially available membranes such as Ultrex CMI-7000 (a copolymer of polystyrene and divinylbenzene) (Yang et al., 2011). Currently available membranes are still too expensive to be profitable on industrial scale. But the search for new, inexpensive materials for production of membranes is still going on.

\subsection{Microbial community}

The operation of BER is based on the efficient transport of electrons produced by microorganisms in catabolic processes. Three different mechanisms of electron transport were identified: direct electron transfer, transport via nanowires and external mediator supported transport.

Microorganisms that use metals as electron acceptors must have developed mechanisms of direct electron transfer to an insoluble solid. The first microorganisms used in BER were Shewanella putrefaciens (Kim et al., 1999). These bacteria are electrochemically active, because their cytochromes are located on the outer cell wall. Direct transport of electrons requires an establishment of a biofilm on the electrode surface. However, biofilm formation on the electrode results in na decrease of substrates and reaction products diffusion rates (Franks and Nevin, 2010). The accumulation of toxic products (such as butanol) may inhibit the metabolism of cells (Rabaey et al., 2011). Electrochemical activity of biofilms appears to be much more complex than expected. Transport of electrons via nanowires is also realised by biofilm creation. Microorganisms forming the outer layers of the biofilm must produce nanopiles, nanowires for the transfer of electrons to the electrode. Conductive nanopiles and nanowires are present in many strains, but their share in the transport of electrons is different in different microorganisms (Lovley, 2008). In the biofilm of Geobacter sulfurreducens nanowires are the only mechanism used by bacteria at large distances from the electrode surface. The strain of Geobacter sulfurreducens KN400 forms a homogeneous biofilm, where nanowires are the dominant form of transport (Franks and Nevin, 2010). On the contrary in Shewanella oneidensis nanowires play a marginal role (Rabaey et al., 2011).

External mediator supported transport is realised through cyclic mediator oxidation and reduction. Bacteria pass electrons to the mediator, which is being reduced. The mediator transports electrons to the anode. As a result, the mediator returns to its oxidised form capable to accept more other electrons. Electron carrier's origin can be exogenic (e.g. methylene blue, neutral red) or endogenic: (sometimes the electron mediator can be synthesised; e.g. in bacteria of the genus the riboflavin is capable of 
mediator synthesis (Lovley, 2008). Populations of bacteria in BER can be very complex. This allows to utilise a wide variety of substrates. Microbes that do not exhibit electrochemical activity can also be present in BER. Some play a positive role, transforming complex substances into easily digestible compounds. But others can provide a competition for electricity-producing bacteria. Examples of such microorganisms are bacteria that carry out methanogenic fermentation. This problem can be solved by introducing methanotrophs into reactor, which will decompose formed methane and transfer electrons to the electrode (Yang et al., 2011).

\section{CONCLUSIONS}

Although bioelectrochemical reactors are still in the early stages of development, numerous attractive applications are of particular interest to both researchers and practitioners. Microorganisms are ubiquitous in the environment and can use various types of substrates, which increases the range of raw materials from which energy can be obtained. Most of BERs do not require expensive noble metals, high prices of which can be a barrier in the dissemination of conventional fuel cells. Bacteria can be treated as self-renewing and self-reproducing catalysts, which ensure sustainability of BERs use. A development of BERs requires both fundamental research and a development of new processes and equipment. Mathematical models can help to better understand the metabolism of microorganisms capable of direct transfer of electrons to the electrode, while on the other hand, they help to optimise performance of BERs. At present the practical use of BERs is limited as they are not capable of generating high energy outputs. As can be seen in Fig. 3 typical values of electrical parameters of MFCs are not sufficient enough to be an independent power source. Therefore, they are used in combination with other non-conventional energy sources (solar panels, etc.). An example of such an application is the Leaf, the latest concept car designed by Shanghai Automotive Industry Corporation (SAIC), where the on-board microbial fuel cells recharge lithium-ion batteries. The example for their use as independent power source is a large scale microbial fuel cell using bottom sediment to power marine measuring and navigation devices, which is working for more than ten years. (Reimers et al., 2001).

This study was supported by the National Centre for Research and Development (Poland) through grant NR 15-0049-10.

\section{REFERENCES}

Franks A.E., Nevin K.P., 2010. Microbial fuel cells, a current review, Energies, 3, 889-919. DOI: 10.3390/en3050899.

Freguia S., Tsujimura S., Kano K., 2010. Electron transfer pathways in microbial oxygen biocathodes. Electrochimica Acta, 55, 813-818. DOI: 10.1016/j.electacta.2009.09.027.

Hamelers H.V.M., Ter Heijne A., Sleutels T.H.J.A., Jeremiasse A.W., Strik D.P.B.T.B., Buisman C.J.N., 2010. New applications and performance of bioelectrochemical systems. Appl. Microbiol. Biotechnol., 85, 1673-1685. DOI: $10.1007 / \mathrm{s} 00253-009-2357-1$.

Kim B.H., Kim H.J., Hyun M.S., Park D.H., 1999. Direct electrode re action of Fe(III)-reducing bacterium, Shewanella putrefaciens. J. Microbial. Biotech., 9, 127-131.

Kim K.-Y., Chae K.-J., Choi M.-J., Ajayi F.F., Jang A., Kim C.-W., Kim I.S., 2011. Enhanced Coulombic efficiency in glucose-fed microbial fuel cells by reducing metabolite electron losses using dual-anode electrodes. Bioresour. Tech., 102, 4144-4149. DOI: 10.1016/j.biortech.2010.12.036.

Lefebvre O., Uzabiaga A., Chang I.S., Kim B., Ng H.Y., 2011. Microbial fuel cells for energy self-sufficient domestic wastewater treatment - a review and discussion from energetic consideration. Appl. Microbiol. Biotechnol., 89, 259-270. DOI: 10.1007/s00253-010-2881-z. 
Li C., Ding L., Cui H., Zhang L., Xu K., Ren H., 2012. Application of conductive polymers in biocathode of microbial fuel cells and microbial community. Bioresour. Technol., 116, 459-465. DOI: 10.1016/j.biortech.2012.03.115.

Liang P., Wang H.Y., Xia X., Huang X., Mo Y. H., Cao X.X., Fan M. Z., 2011. Carbon nanotube powders as electrode modifier to enhance the activity of anodic biofilm in microbial fuel cells. Biosens. Bioelectron., 26, 3000-3004. DOI: 10.1016/j.bios.2010.12.002.

Liu J., Qiao Y., Guo C.X., Lim S., Song H., Li C. M., 2012. Graphene/carbon cloth anode for high-performance mediatorless microbial fuel cells. Bioresour. Technol., 114, 275-280, DOI: 10.1016/j.biortech.2012.02.116.

Logan B. E., Hamelers B., Rozendal R., Schröder U., Keller J., Freguia S., Aelterman P., Verstraete W., Rabaey K., 2006. Microbial fuel cells: methodology and technology. Environ. Sci. Technol., 40, 5181-5192. DOI: $10.1021 / \mathrm{es} 0605016$.

Logan B.E., 2010. Scaling up microbial fuel cells and other bioelectrochemical systems, Appl. Microbiol. Biotechnol., 85, 1665-1671. DOI: 10.1007/s00253-009-2378-9.

Lovley B.E., 2008. The microbe electric: conversion of organic matter to electricity. Current Opinion Biotechnol., 19, 564-571. DOI: 10.1016/j.copbio.2008.10.005.

Lowy D.A., Tender L.M., 2008. Harvesting energy from the marine sediment-water interface: III. Kinetics activity of quinone- and antimony-based anode materials. J. Power Sources, 185, 70-75. DOI: 10.1016/j.jpowsour.2008.06.079.

Nevin K.P., Woodard T.L., Franks A.E., Summers Z.M., Lovley D.R., 2010. Microbial electrosynthesis: Feedin microbes electricity to convert carbon dioxide and water to multicarbon extracellular organic compounds. $\mathrm{mBio}$, 1, e00103-10. DOI: $10.1128 / \mathrm{mBio} .00103-10$.

Rabaey K., Girguis P., Nielsen L.K., 2011. Metabolic and practical considerations on microbial electrosynthesis. Current Opinion in Biotechnol., 22, 371-377. DOI: 10.1016/j.copbio.2011.01.010.

Reimers C.E., Tender L.M., Ferting S., Wang W., 2001. Harvesting energy from the marine sediment-water interface. Environ. Sci. Technol., 35, 192-195. DOI: 10.1021/es001223s.

Rozendal R.A., Hamelers H.V.M., Buisman C.J.N., 2006. Effects of membrane cation transport on pH and microbial fuel cell performance. Environ. Sci. Technol., 40, 5206-5211. DOI: 10.1021/es060387r.

Rozendal R.A., Jeremiasse A.W., Hamelers H.V.M., Buisman C.J.N., 2008. Hydrogen production with a microbial biocathode. Environ. Sci. Technol., 42, 629-634. DOI: 10.1021/es071720+.

Tang X., Guo K., Li H., Du Z., Tian J., 2011. Electrochemical treatment of graphite to enhance electron transfer from bacteria to electrodes. Bioresour. Technol., 102, 3558-3560. DOI: 10.1016/j.biortech.2010.09.022.

ter Heijne A., Hamelers H.V.M., Saakes M., Buisman C.J.N., 2008. Performance of non-porous graphite and titanium-based anodes in microbial fuel cells. Electrochimica Acta, 53, 5697-5703. DOI: 10.1016/j.electacta.2008.03.032.

Wang H-Y., Bernarda A., Huang C-Y., Li D-J., Chang J-S., 2011. Micro-sized microbial fuel cell: A mini review. Bioresour. Technol., 102, 235-243. DOI: 10.1016/j.biortech.2010.07.007.

Wang X., Cheng SA., Feng Y.J., Merrill M.D., Saito T., Logan B.E., 2009. Use of carbon mesh anodes and the effect of different pretreatment methods on power production in microbial fuel cells. Environ. Sci. Technol., 43, 6870-6874. DOI: $10.1021 / \mathrm{es} 900997 \mathrm{w}$.

Wei J., Liang P., Huang X., 2011. Recent progress in electrodes for microbial fuel cells. Bioresour. Technol., 102, 9335-9344. DOI: 10.1016/j.biortech.2011.07.019.

Yang Y., Sun G., Xu M., 2011. Microbial fuel cells come of age. J. Chem. Technol. Biotechnol., 86, 625-632. DOI: $10.1002 /$ jetb.2570. 